\title{
Intramucosal Poorly Differentiated Adenocarcinomas Detected in a Patient with Long-Standing Ulcerative Colitis
}

\author{
Junichi Zaitsu ${ }^{a}$ Kazuya Kuraoka $^{a}$ b Akira Ishikawa $^{b}$ Hideki Yamamoto $^{a}$

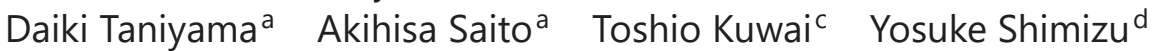 \\ Hirotaka Tashiro ${ }^{d}$ Kiyomi Taniyamaa, e \\ aDepartment of Diagnostic Pathology, National Hospital Organization, Kure Medical Center \\ and Chugoku Cancer Center, Kure, Japan; bepartment of Clinical Laboratory, National \\ Hospital Organization, Kure Medical Center and Chugoku Cancer Center, Kure, Japan; \\ 'Department of Gastroenterology, National Hospital Organization, Kure Medical Center \\ and Chugoku Cancer Center, Kure, Japan; 'Department of Surgery, National Hospital \\ Organization, Kure Medical Center and Chugoku Cancer Center, Kure, Japan; eHonorary \\ President, National Hospital Organization, Kure Medical Center and Chugoku Cancer \\ Center, Kure, Japan
}

\section{Keywords}

Adenocarcinoma · Dysplasia $\cdot$ Endoscopic submucosal dissection · Ulcerative colitis

\begin{abstract}
We report a case of long-standing ulcerative colitis with intramucosal well- and poorly differentiated adenocarcinomas detected over a 6-month duration. A Japanese man in his sixties with a 31-year history of ulcerative colitis had a $1.1-\mathrm{cm}$-sized intramucosal well-differentiated tubular adenocarcinoma in the rectum resected by endoscopic submucosal dissection. At the follow-up colonoscopy, a biopsy near the endoscopic submucosal dissection scar revealed poorly differentiated adenocarcinoma, and a total proctocolectomy was performed 6 months after the endoscopic submucosal dissection. The whole colorectal pathological exam showed 2 flat foci of intramucosal poorly differentiated adenocarcinoma, 4 and $2 \mathrm{~mm}$ in size each, near the endoscopic submucosal dissection scar in the rectum, and an increased number of Paneth cells, thickened muscularis mucosa, and widening of the distance between the gland base and muscularis mucosa in the transverse colon to the rectum. Adenocarcinomas were not found in areas where architecturally severe changes of the mucosa or the highest number of Paneth cells proliferation were detected. Multiple biopsies using magnifying narrow band imaging or crystal violet staining around the initial high-grade dysplasia or intramucosal adenocarcinoma were effective to find other lesions, such as poorly differentiated adenocarcinoma foci in the mucosa in a long-standing ulcerative colitis patient.
\end{abstract}

(C) 2020 The Author(s).

Published by S. Karger AG, Basel 


\section{Case Reports in Oncology}

\begin{tabular}{l|l}
\hline Case Rep Oncol 2020;13:1176-1184 \\
\hline DOI: 10.1159/000510305 & $\begin{array}{l}\text { ○ 2020 The Author(s). Published by S. Karger AG, Basel } \\
\text { www.karger.com/cro }\end{array}$ \\
\hline
\end{tabular}

Zaitsu et al.: Intramucosal Adenocarcinomas Detected in a Patient with Ulcerative Colitis

\section{Introduction}

The number of patients with ulcerative colitis (UC) is increasing year by year [1]. Longstanding UC induces colorectal cancer, and an intramucosal tumor due to UC is called dysplasia. Riddell et al. [2] advocated the classification of dysplasia by the degree of atypia; low-grade dysplasia (LGD) and high-grade dysplasia. The treatment for high-grade dysplasia has been a total colectomy, but endoscopic submucosal dissection (ESD) is considered for resectable dysplasia in recent years [3, 4]. We report a case of long-standing UC with intramucosal (pTis) well- (Tub1) and poorly (Por) differentiated adenocarcinomas detected over a 6-month duration with whole colorectal pathological examination.

\section{Case Report}

\section{UC Arm}

Initially, a Japanese man in his thirties complained of bloody stool and visited our hospital in the year X-31. He received symptomatic treatment. However, details of the clinical history in the years X-31 to X-13 were unclear. He complained again of bloody stool and diarrhea in the year X-13 and was diagnosed as rectal UC. He visited an outpatient unit every month or every 3 months. Sometimes, he complained of diarrhea 10 times at the most per day for several days to 3 months. He has been medicated by an internal use of mesalazine from the years X-13 to X. He was administered mesalazine enema for 2 months in the year X-2 and adrenocorticosteroid enema for 11 months in the year X-1 concurrently. Over the recent 8 years, he underwent total colonoscopy every 1 or 2 years and revealed active inflammation from the hepatic flexure to the rectum between the years X-4 and X-2. In other periods, the active inflammation was detected from the descending colon to the rectum. The Matts grades [5] were evaluated several times as shown in Table 1.

\section{Cancer Arm}

Colonoscopy revealed a 1.1-cm-sized pTisTub1 in the rectum (Fig. 1a) in February of the year X. He was admitted to our hospital in April, and this initial rectal cancer was consequently resected by ESD (Fig. 1b). In October, multiple biopsies using narrow band imaging performed at the post-ESD colonoscopy detected Por near the ESD scar, and a total colectomy

Table 1. Matts grade for recent 8 years in the colorectum

\begin{tabular}{llllll}
\hline Year/month & \multicolumn{5}{l}{ Matts grade (macro/micro) } \\
\cline { 2 - 5 } & $\mathrm{A}$ & $\mathrm{T}$ & $\mathrm{D}$ & $\mathrm{S}$ & $\mathrm{R}$ \\
\hline $\mathrm{X}-8 / 05$ & $1 / 1$ & $1 / 1$ & $1 / 1$ & $1 / 1$ & $2 / 1$ \\
$\mathrm{X}-7 / 05$ & $1 / \mathrm{ND}$ & $1 / \mathrm{ND}$ & $1 / \mathrm{ND}$ & $1 / \mathrm{ND}$ & $3 / 5$ \\
$\mathrm{X}-6 / 08$ & $1 / 2$ & $1 / 4$ & $3 / 4$ & $3 / 4$ & $3 / 5$ \\
$\mathrm{X}-4 / 07$ & $1 / 2$ & $3 / 3$ & $3 / 3$ & $3 / 3$ & $3 / 3$ \\
$\mathrm{X}-3 / 07$ & $1 / \mathrm{ND}$ & $3 / 4$ & $3 / \mathrm{ND}$ & $2 / 1$ & $1 / 1$ \\
$\mathrm{X}-2 / 06$ & $1 / \mathrm{ND}$ & $3 / \mathrm{ND}$ & $3 / \mathrm{ND}$ & $3 / \mathrm{ND}$ & $3 / \mathrm{ND}$ \\
$\mathrm{X}-1 / 01$ & $1 / \mathrm{ND}$ & $1 / \mathrm{ND}$ & $2 / \mathrm{ND}$ & $3 / \mathrm{ND}$ & $3 / 5$ \\
$\mathrm{X} / 02$ & $1 / \mathrm{ND}$ & $1 / \mathrm{ND}$ & $1 / \mathrm{ND}$ & $1 / \mathrm{ND}$ & $1 / \mathrm{ND}$ \\
\hline
\end{tabular}

$\mathrm{X}$, the year the patient was admitted; $\mathrm{A}$, ascending colon; T, transverse colon; $\mathrm{D}$, descending colon; $\mathrm{S}$, sigmoid colon; R, rectum; ND, not done; macro, macroscopic; micro, microscopic findings. 


\section{Case Reports in Oncology}

\begin{tabular}{l|l}
\hline Case Rep Oncol 2020;13:1176-1184 \\
\hline DOI: 10.1159/000510305 & $\begin{array}{l}\text { @ 2020 The Author(s). Published by S. Karger AG, Basel } \\
\text { www.karger.com/cro }\end{array}$ \\
\hline
\end{tabular}

Zaitsu et al.: Intramucosal Adenocarcinomas Detected in a Patient with Ulcerative Colitis
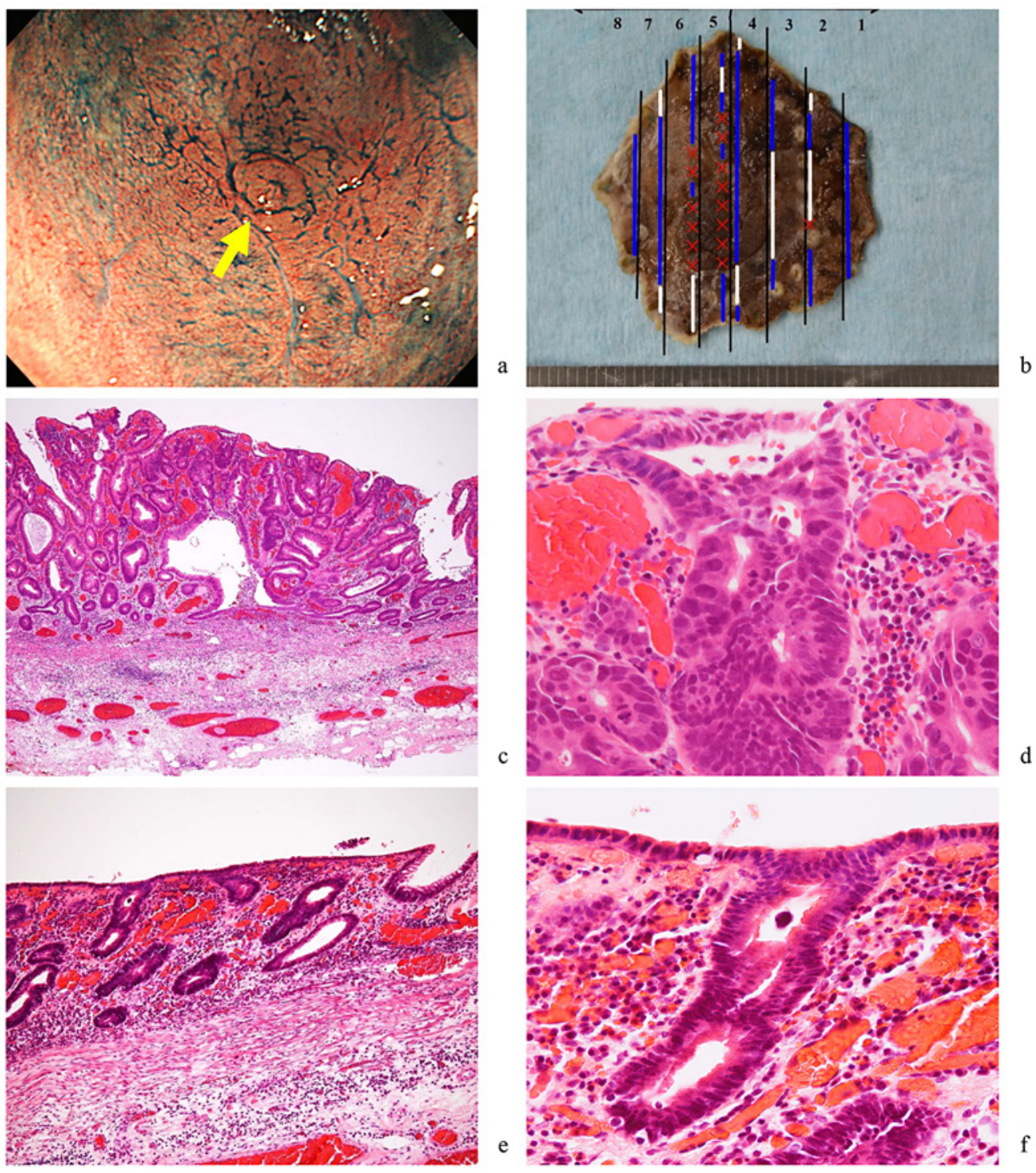

Fig. 1. Endoscopic and pathological findings of the initial rectal adenocarcinoma. A flat elevated tumor (arrow) of $1.1 \mathrm{~cm}$ in size was detected by a total colonoscopy with indigo carmine (a). Distribution of several lesions in the specimen obtained by an endoscopic submucosal dissection (ESD). Red crosses show intramucosal well-differentiated tubular adenocarcinoma, blue lines show low-grade dysplasia, and white lines show erosion (b). Microscopic findings of the initial rectal adenocarcinoma showing an intramucosal well-differentiated tubular adenocarcinoma $(\mathbf{c}, \mathbf{d})$ and low-grade dysplasia $(\mathbf{e}, \mathbf{f})$.

was performed in December (Fig. 2). He survives without recurrence and metastasis of cancer for 48 months, although he was hospitalized once due to ileus 15 months after total colectomy.

\section{Past Cancer and Family History}

The patient underwent distal gastrectomy in the year X-15 due to a 4-mm-sized intramucosal signet ring cell carcinoma (Sig). ESD of the remnant stomach in August of the year X revealed an 8-mm-sized intramucosal Sig, which was a second primary Sig, prior to the rectal ESD. He had no family history of malignancy nor UC. 


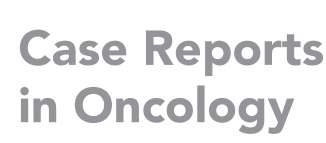

\begin{tabular}{l|l}
\hline Case Rep Oncol 2020;13:1176-1184 \\
\hline DOI: 10.1159/000510305 & $\begin{array}{l}\text { ○ 2020 The Author(s). Published by S. Karger AG, Basel } \\
\text { www.karger.com/cro }\end{array}$ \\
\hline
\end{tabular}

Zaitsu et al.: Intramucosal Adenocarcinomas Detected in a Patient with Ulcerative Colitis

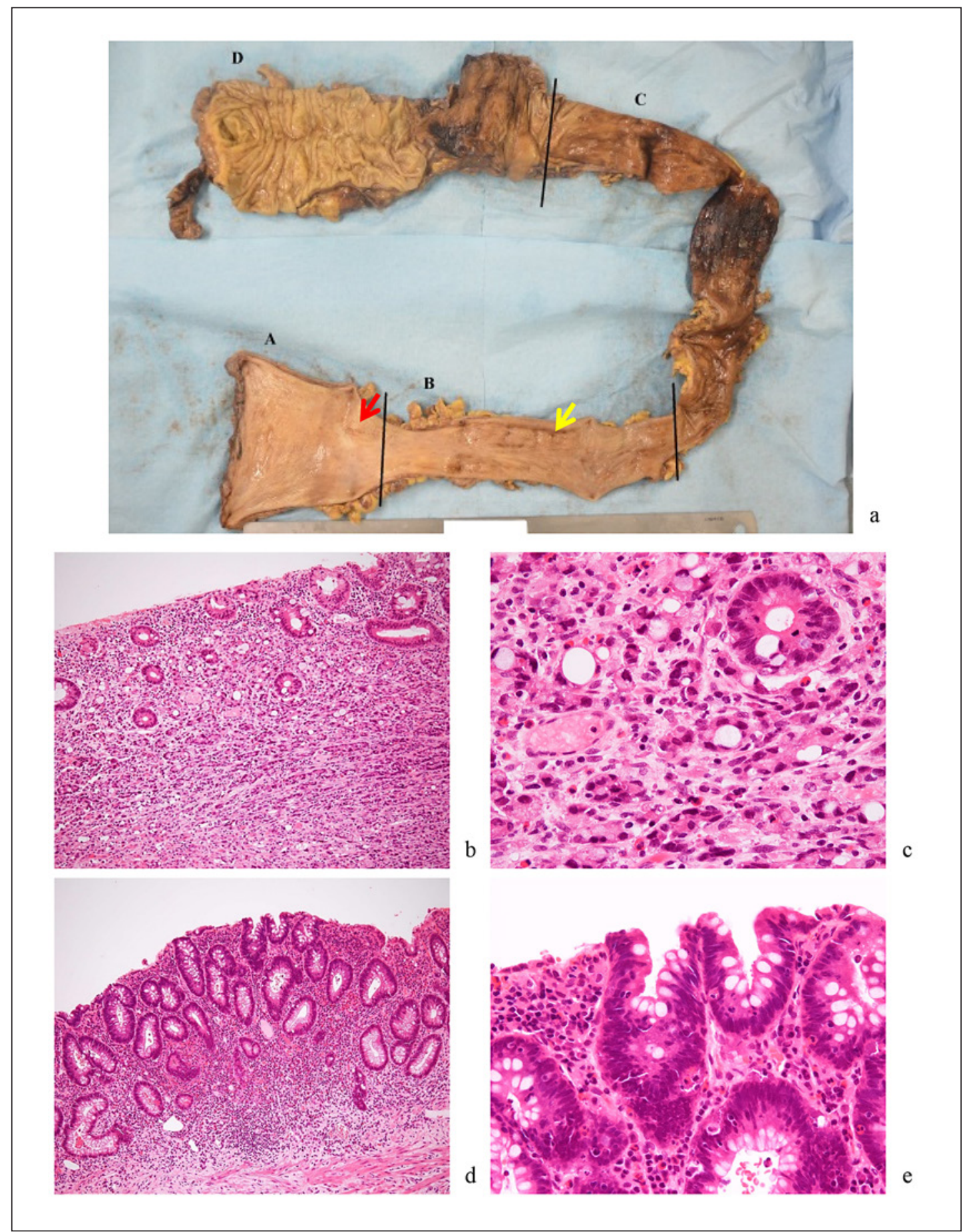

Fig. 2. Pathological findings of the total colectomy specimens. The parts of the colorectum were named $A$ (rectum), B (descending to sigmoid colon), C (transverse to descending colon), and D (ascending colon). Intramucosal hemorrhage anxrefd constriction were observed from the transverse to the descending colon. Two foci of intramucosal poorly differentiated adenocarcinoma were detected near the ESD scar (a, red arrow). Low-grade dysplasia was detected in the sigmoid colon (a, yellow arrow). Intramucosal poorly differentiated adenocarcinomas 4 and $2 \mathrm{~mm}$ in size were detected near the rectal ESD scar (b, c), and invisible low-grade dysplasia was detected in the sigmoid colon $(\mathbf{d}, \mathbf{e})$. 


\section{Case Reports in Oncology}

\begin{tabular}{l|l}
\hline Case Rep Oncol 2020;13:1176-1184 \\
\hline DOI: 10.1159/000510305 & $\begin{array}{l}\text { @ } 2020 \text { The Author(s). Published by S. Karger AG, Basel } \\
\text { www.karger.com/cro }\end{array}$ \\
\hline
\end{tabular}

Zaitsu et al.: Intramucosal Adenocarcinomas Detected in a Patient with Ulcerative Colitis

Pathological Findings

\section{Samples}

Immediately after ESD or operation, tissues were fixed in 10\% formalin neutral buffer solution for 1 day for the ESD specimen and rectum, for 5 days for parts of the transverse and descending colon with hemorrhage or constriction, for 8-19 days for the ascending colon, for 27 days for the descending to sigmoid colon, and for 29-34 days for the transverse colon. All tissues fixed were then cut sequentially and embedded in paraffin. One to 5 days' fixation in $10 \%$ formalin neutral buffer solution was done to make a pathological report within 2 weeks after the resection to respond to the clinical request. Other longer tissue fixations were done to examine details of mucosal change due to the long-standing UC. Finally, we made a total of 183 paraffin-embedded tissue blocks.

Each paraffin-embedded tissue of the colorectum had 1.0-3.0 cm length of muscularis mucosae (MM), and we divided each specimen into 2-4 sections to make the lengths of the sections uniform (5-7 mm). We counted the number of Paneth cells (PC) and measured the thickness of the MM and the distance between the gland base and the MM using a microscopyattached digital camera and its associated software (Olympus CellSens ${ }^{\circledR}$ imaging software version 1.14, Olympus, Tokyo, Japan). The number of PC, thickness of the MM, and the distance between the gland base and the MM were measured when the colorectal glands were observed to stand at an upright position. Diagonally located or eroded glands were out of examination. These values were confirmed by 2 pathologists (J.Z. and K.T.). Comprehensive agreement for the research use of resected materials was obtained from the patient by our institution [6].

\section{Immunohistochemistry}

Serial sections from a representative paraffin block were used to assess Ki-67 and p53 expression. After reaction with blocking buffer, these tissue sections were incubated with antibodies against Ki-67 (Clone MIB-1, DAK0, Tokyo, Japan; 1:50) and p53 (Clone D0-7, DAKO, Tokyo, Japan; 1:50) using Ventana BenchMark SS ${ }^{\circledR}$ autostainer (Roche, Tokyo, Japan) in accordance with the manufacturer's guidelines.

\section{Results}

The ESD specimen revealed a flat elevated tumor $1.1 \mathrm{~cm}$ in size, and the tumor thickness was $1.5 \mathrm{~mm}$ (Fig. 1b). The histological exam revealed pTisTub1 (Fig. 1c, d). Although the horizontal and vertical margins were negative for cancer, LGD and erosion were distributed irregularly around the pTisTub1 (Fig. 1e,f). On immunohistochemistry, the dysplastic glands were diffusely positive for $\mathrm{p} 53$, and Ki-67 was positive on the lower half of the glands. Some of the p53-positive LGD glands were exposed on the horizontal margin.

The total colectomy specimen showed an ulcer scar due to ESD in the rectum. On macroscopic examination, no obvious tumor was detected. Intramucosal hemorrhage and stricture were observed from the transverse to the sigmoid colon (Fig. 2a). Microscopically, there were 2 foci of pTisPor, 4 and $2 \mathrm{~mm}$ in size each, near the ESD scar (Fig. 2b, c), and LGD spread between them. No lymphovascular invasion nor lymph node metastasis of carcinoma was observed. There was another small LGD on the oral side of the sigmoid colon (Fig. 2d, e). Acute intramucosal hemorrhage, erosion, and multifocal submucosal fibrosis without dysplasia were observed in the transverse colon.

The distribution of density of PC, the thickness of the MM, and the distance between the gland base and the MM are shown in Figure 3. An increased number of PC, thickened MM, and widening of the distance between the gland base and the MM were found from the hepatic

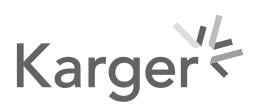




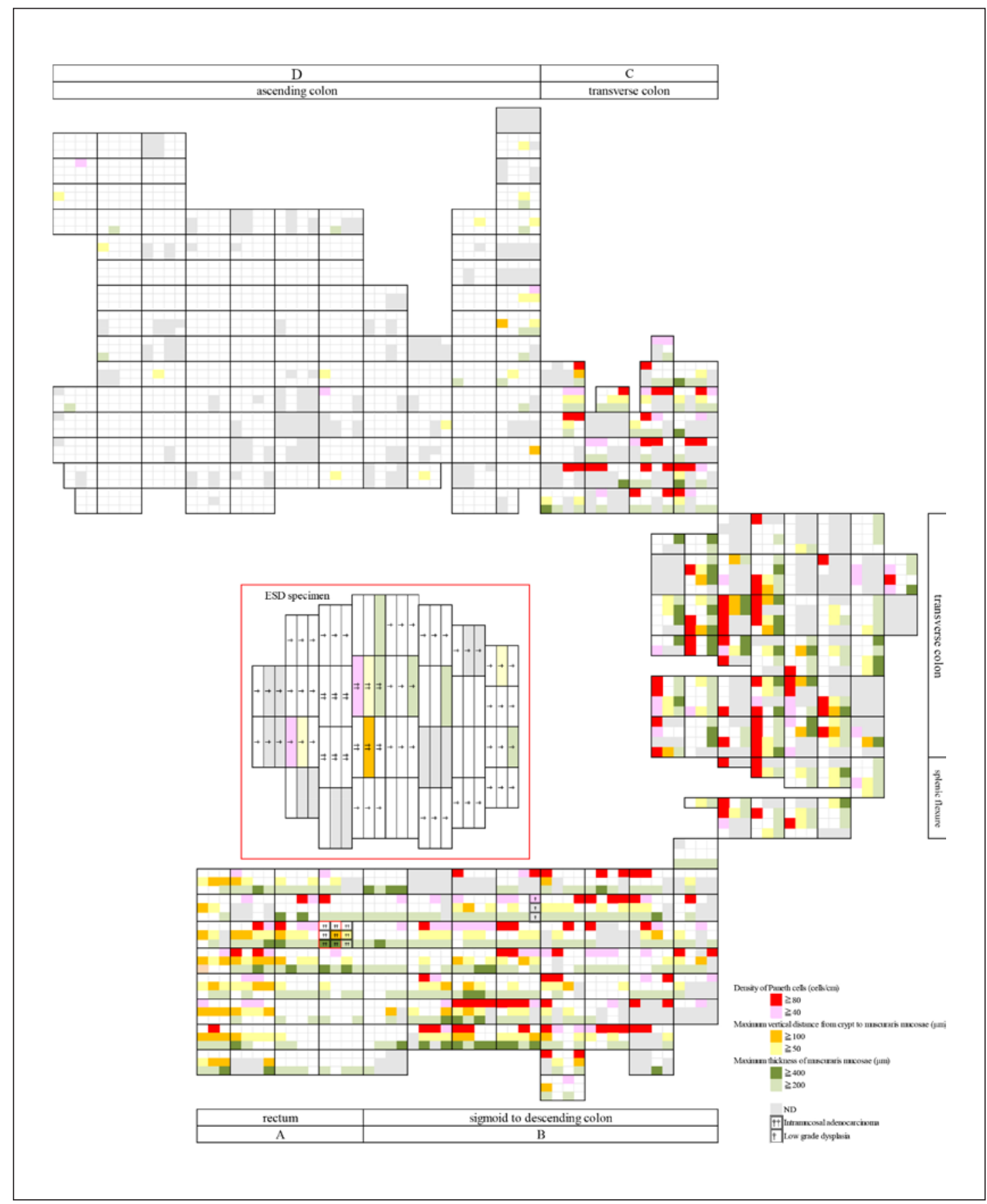

Fig. 3. The distribution of Paneth cells (PC), the thickness of the muscularis mucosae (MM), and the distance between the gland base and the MM. Thickening of the MM and widening of the distance between the gland base and the MM were measured when the colorectal glands were observed to stand at an upright position. The maximum distances of them in each 5- to 7-mm section of the whole colectomy specimen were recorded. An increased number of PC was observed at the gland base from the transverse colon to the rectum. Their pathological abnormalities were detected from the hepatic flexure to the rectum and were most remarkable in the transverse colon. Initial ESD specimen was obtained from the red square region of the rectum. 
flexure to the rectum. The 2 pTisPor occurred in the area of thickened MM and the distance between the gland base and the MM was greater than $100 \mu \mathrm{m}$. In the ascending colon, none of the histological changes mentioned above were found.

\section{Discussion/Conclusion}

UC causes chronic mucosal inflammation, repeated destruction and regeneration of glands. It also induces a meandering of the glands, PC metaplasia, thickening of the MM, and widening of the distance between the gland base and the MM [7]. The Montreal classification of inflammatory bowel disease classified UC as proctitis (E1), left-sided colitis (E2), and extension beyond the splenic flexure (E3) based on the endoscopic extent of inflammation [8]. The extent of colitis is an independent risk factor for cancerization [9]. The endoscopic extent of inflammation of UC tends to be underestimated compared to histological examination [10], and the identification of the histological extent may be important to estimate the risk of cancerization and dysplasia and prognosis [11].

In the present case, $\mathrm{PC}$ metaplasia, thickened MM, and widening of the distance between the gland base and the MM were found from the hepatic flexure to the rectum, along with the maximum range of endoscopic active inflammation observed from the year X-4 to X-2. However, the range of endoscopic active inflammation was limited from the descending colon to the rectum (left-sided colon) for 6 of the recent 8 years, such that this patient was considered to be in the E3 group; a high-risk patient of colorectal cancer. PC metaplasia is most conspicuous in the transverse to sigmoid colon. Thickening of the MM and widening of the distance between the gland base and the MM were remarkable in the transverse colon and part of the left-sided colon. However, the pTisPor and LGD were detected in the rectum and sigmoid colon, respectively.

In the dysplasia-carcinoma sequence of UC, p53 gene mutation occurs in an earlier phase of cancerization compared to an adenoma-carcinoma sequence [12]. Mitsuhashi et al. [13] reported that patients with colorectal cancer or dysplasia due to left-sided or pancolitis of UC tend to have a higher p53 immunostaining-positive ratio in rectal glandular cells compared to patients without dysplasia. Additionally, they reported that the density and height of the glands, density of the $\mathrm{PC}$, and thickness of the MM of the rectum corresponded to disease duration, and they did not correspond to the coexistence of colorectal cancer or dysplasia directly but correlated with p53 positivity of the rectal glandular cells. In UC patients, these histological regenerative changes may suggest a higher frequency of the p53 mutation and might be a risk of developing dysplasia and colorectal cancer in the future.

In the present case, pTisTub1 and subsequent pTisPor occurred in the rectum, where the thickened MM and widening of the distance between the gland base and the MM were detected. However, these histological changes and PC metaplasia are most remarkable in the transverse colon rather than the rectum and sigmoid colon.

The recent European Crohn's and Colitis Organization (ECCO) guideline [3] and Surveillance for Colorectal Endoscopic Neoplasia Detection and Management in Inflammatory Bowel Disease Patients (SCENIC) international consensus statement [4] recommend ESD for the treatment of endoscopically resectable polypoid dysplastic lesions and subsequent surveillance colonoscopy rather than total colectomy. The Paris classification [14] classified dysplasia into visible and invisible dysplasia, and classified visible dysplasia into polypoid and nonpolypoid types. The nonpolypoid dysplasia, lesions with little $(<2.5 \mathrm{~mm})$ or no protrusion above the mucosa, have a higher risk of synchronous or metachronous cancer than polypoid dysplasia. The ECCO guideline recommends that UC patients with endoscopically unresectable nonpolypoid dysplasia should undergo colectomy regardless of the grade of dysplasia

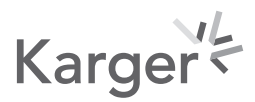


[3]. In the present case, the height of the initial rectal pTisTub1 was $<2.5 \mathrm{~mm}$, and the size was $>1 \mathrm{~cm}$. Therefore, this patient was considered to need surgical treatment.

Two foci of pTisPor were found only 6 months after initial ESD. Invisible pTisPor might have been present when ESD was performed for the initial pTisTub1. Some reports recommend random biopsy around the ESD area to detect the other dysplastic lesions [11]. Although pTisPor and pTisSig are rare in colorectal cancers, they were more frequently detected in UC patients than sporadic cases. Sugimoto et al. [15] reported 4 of 54 cases (7.4\%) of intramucosal carcinoma in UC patients were Por or Sig. They also reported the depressed appearance with white light, Vn (obviously nonstructured) pit pattern with crystal violet staining, and amorphous surface pattern with magnifying narrow band imaging as endoscopic features of pTisPor and pTisSig in UC patients. Using magnifying narrow band imaging or crystal violet staining is considered to be useful when performing biopsy around the ESD area. In the present case, a random biopsy using magnifying narrow band imaging or crystal violet staining around the ESD area was effective to detect pTisPor.

\section{Acknowledgement}

We are grateful to Ms. Kazue Iwahiro, Mr. Hiroki Fujisawa, Ms. Arisa Kan, Ms. Naoko Yasumura, Mr. Akihiro Kagawa, Ms. Haruna Shima, Ms. Mikie Shitaune, Ms. Yoko Kodama, Ms. Tamaki Toda, and Ms. Naoko Kishida; the staff of the Department of Pathology and Institution for Clinical Research of Kure Medical Center and Chugoku Cancer Center for their technical assistance.

\section{Statement of Ethics}

Comprehensive agreement for the research use of resected materials was obtained from the patient by our institution. Written informed consent was given by the patient to publish his case information and details.

\section{Conflict of Interest Statement}

The authors declare no conflicts of interest.

\section{Author Contributions}

J.Z. and K.T. acquired and analyzed all the data. All authors contributed to conception and design of the study. J.Z. wrote the manuscript, which was critically revised by K.T. and K.K. All authors agreed to the final version of the manuscript, and agreed to be accountable for all aspects of the work.

\section{Karger's}




\section{Case Reports in Oncology}

\begin{tabular}{l|l}
\hline Case Rep Oncol 2020;13:1176-1184 \\
\hline DOI: 10.1159/000510305 & $\begin{array}{l}\text { @ 2020 The Author(s). Published by S. Karger AG, Basel } \\
\text { www.karger.com/cro }\end{array}$ \\
\hline
\end{tabular}

Zaitsu et al.: Intramucosal Adenocarcinomas Detected in a Patient with Ulcerative Colitis

\section{References}

1 Molodecky NA, Soon IS, Rabi DM, Ghali WA, Ferris M, Chernoff G, et al. Increasing incidence and prevalence of the inflammatory bowel diseases with time, based on systematic review. Gastroenterology. 2012;142(1):46e30.

2 Riddell RH, Goldman H, Ransohoff DF, Appelman HD, Fenoglio CM, Haggitt RC, et al. Dysplasia in inflammatory bowel disease: standardized classification with provisional clinical applications. Hum Pathol. 1983;14(11): 931-68.

3 Magro F, Gionchetti P, Eliakim R, Ardizzone S, Armuzzi A, Barreiro-de Acosta M, et al. Third European Evidencebased Consensus on Diagnosis and Management of Ulcerative Colitis. Part 1: Definitions, Diagnosis, Extraintestinal Manifestations, Pregnancy, Cancer Surveillance, Surgery, and Ileo-anal Pouch Disorders. J Crohns Colitis. 2017;11(6):649-70.

4 Laine L, Kaltenbach T, Barkun A, McQuaid KR, Subramanian V, Soetikno R. SCENIC international consensus statement on surveillance and management of dysplasia in inflammatory bowel disease. Gastrointest Endosc. 2015;81(3):489.

5 Matts SG. The value of rectal biopsy in the diagnosis of ulcerative colitis. Q J Med. 1961;30:393-407.

6 Taniyama K, Ishida K, Toda T, Motoshita J, Kuraoka K, Saito A, et al. Tyrosine1248-phosphorylated HER2 expression and HER2 gene amplification in female invasive ductal carcinomas. Breast Cancer. 2008;15(3): 231-40.

7 Ajioka Y, Nishikura K, Watanabe G. [Pathomorphology of ulcerative colitis]. Nippon Rinsho. 2005;63(5): 763-9.

8 Satsangi J, Silverberg MS, Vermeire S, Colombel JF. The Montreal classification of inflammatory bowel disease: controversies, consensus, and implications. Gut. 2006;55(6):749-53.

9 Yashiro M. Ulcerative colitis-associated colorectal cancer. World J Gastroenterol. 2014;20(44):16389-97.

10 Mathy C, Schneider K, Chen YY, Varma M, Terdiman JP, Mahadevan U. Gross versus microscopic pancolitis and the occurrence of neoplasia in ulcerative colitis. Inflamm Bowel Dis. 2003;9(6):351-5.

11 Shergill AK, Shergill AK, Lightdale JR, Bruining DH, Acosta RD, Chandrasekhara V, et al. The role of endoscopy in inflammatory bowel disease. Gastrointest Endosc. 2015;81(5):1101.

12 Kobayashi K, Tomita H, Shimizu M, Tanaka T, Suzui N, Miyazaki T, et al. p53 Expression as a Diagnostic Biomarker in Ulcerative Colitis-Associated Cancer. Int J Mol Sci. 2017;18(6):pii: E1284.

13 Mitsuhashi J, Mikami T, Saigenji K, Okayasu I. Significant correlation of morphological remodeling in ulcerative colitis with disease duration and between elevated p53 and p21 expression in rectal mucosa and neoplastic development. Pathol Int. 2005;55(3):113-21.

14 The Paris endoscopic classification of superficial neoplastic lesions: esophagus, stomach, and colon: November 30 to December 1, 2002. Gastrointest Endosc. 2003;58(6 Suppl 1):S3-43.

15 Sugimoto S, Shimoda M, Iwao Y, Mutaguchi M, Nanki K, Mizuno S, et al. Intramucosal poorly differentiated and signet-ring cell components in patients with ulcerative colitis-associated high-grade dysplasia. Dig Endosc. 2019;31(6):706-11. 